\title{
Ecological factors determining the density-distribution of Central European dragonflies (Odonata)
}

\author{
FILIP HARABIŠ $\check{1}^{1}$ and ALEŠ DOLNÝ² \\ ${ }^{1}$ Department of Ecology, Czech University of Life Sciences Prague, Kamýcká 129, 16521 Praha 6 - Suchdol, Czech Republic, \\ e-mail: harabis.f@gmail.com \\ ${ }^{2}$ Department of Biology and Ecology, University of Ostrava, Chittussiho 10, 71000 Ostrava; e-mail: ales.dolny@osu.cz
}

Key words. Habitat specificity, niche breath, Odonata, relative distribution, dragonflies

\begin{abstract}
Habitat specificity is the most important factor affecting the regional distribution of dragonflies. Nevertheless, species with the highest specificity are not always the scarcest. Several important determinants of dragonfly density-distribution relationships were identified. Altitude preference and altitude range are significantly associated with dragonfly distribution. Some of the species that are habitat specialists but occur over a wide range of altitudes should be classified as rare but not endangered. This very simple principle is based on the assumption that habitat specialists have a very limited number of suitable biotopes. Obviously, dragonflies with a marginal distribution prefer a narrow range of altitudes (especially in terms of temperature limitation) and biotopes (effect of biogeography, marginality). Surprisingly, there is no "critical" life stage that is significantly associated with the regional distribution of dragonflies, although most species spend most time in the larval stage. Knowledge of the dispersal ability of particular species is limited, although it could significantly affect species survival and distribution.
\end{abstract}

\section{INTRODUCTION}

Dragonflies (Odonata) are increasingly being used as indicators of stability of water biotopes (Bried et al., 2007; Hassall et al., 2010; Sahlen \& Ekestubbe, 2001; Smith et al., 2007; D'Amico et al., 2004; Wildermuth, 2001) and of global warming (Hickling et al., 2005). Dragonfly larvae live in water and the adults are good dispersers (Corbet, 1999). Dragonflies use almost all types of freshwater biotopes. Some specialise in different types of lotic (flowing) water, from rivulets to large streams; others use lentic ecosystems, including lakes, ponds and reservoirs as well as temporary water bodies such as puddles, rain water in containers, phytotelmata (water in plant receptacles) or lithotelms (water in rock crevices). Some species prefer water biotopes with extreme conditions, including alpine peat bogs with acidic water, or secondary biotopes that are closely connected with anthropogenic activities (Corbet, 1999; Dolný et al., 2007).

Even though dragonflies are frequently used as bioindicators, the effect of individual environmental and demographic factors on their distribution remains unclear. Keil et al. (2008) identify the water-energy balance (ecosystem productivity) as the strongest environmental correlate of dragonfly species richness and distribution. That ecosystem productivity greatly affects species richness is true for most insect orders (Whittaker et al., 2007). This relationship is strong at the global scale but less strong at regional and local scales because of the increasing effect of other ecological factors.

One frequently emphasized local factor that influences dragonfly distribution is the vegetation growing at the edges of water bodies (Corbet, 1999). Several studies (for example Schindler et al., 2003) note that the type and structure of this vegetation directly influences the species richness and distribution of dragonflies. The macrophyte vegetation provides shelter for larvae and adults. There is also evidence that dragonfly species richness rapidly declines when the cover of macrophyte vegetation declines (Foote \& Hornung, 2005).

Determining which factors influence dragonfly distribution at the regional scale is difficult. The influences of dispersal (Conrad et al., 1999, 2002; McPeek, 1989), phenology (Dingemanse \& Kalkman, 2008), predation risk (Johansson et al., 2006; McCauley, 2007; Thompson, 1990) or other factors (Remsburg et al., 2008) are difficult to estimate at the regional scale and can only be quantified by examining local distribution patterns.

The main goal of this study was to identify the important determinants of dragonfly density and distribution based on the regional distribution of dragonflies in the Czech Republic.

\section{MATERIAL AND METHODS}

\section{Study area}

The data used is that which describes the relative distribution (the number of vacant quadrats for a particular species/sum of all vacant quadrats) of dragonflies in the Czech Republic (Fig. 1). The Czech Republic, has an area of $79000 \mathrm{~km}^{2}$ and is located in Central Europe. Almost 90 percent of the area is at altitudes between 200-700 m (Fig. 1). The diversity of water biotopes is relatively high because the climate is mild and moist and the resultant high diversity of water biotypes is associated with a high species richness of dragonflies. The database includes the occurrence of 73 dragonfly species, with that of 70 species recently confirmed (Dolný et al., 2007). 
A

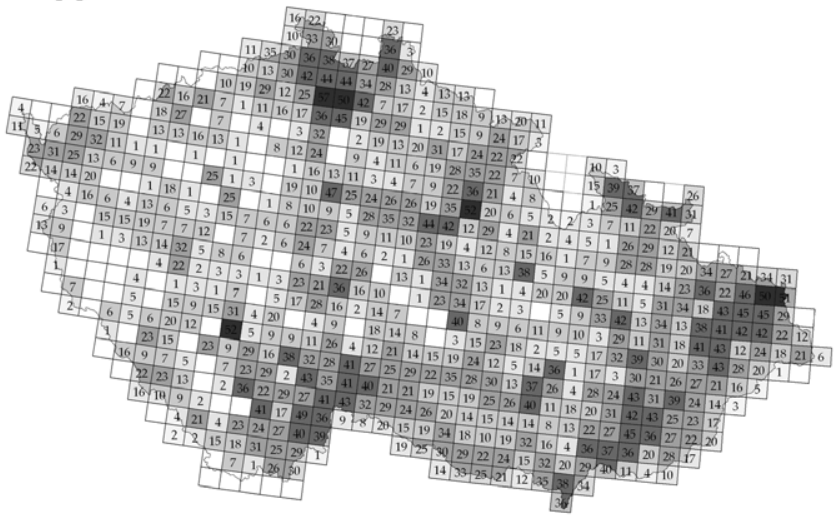

C

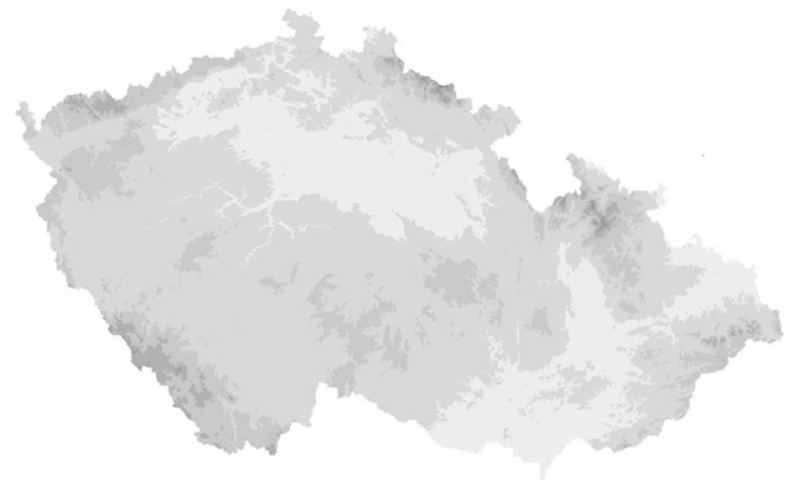

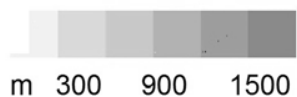

B

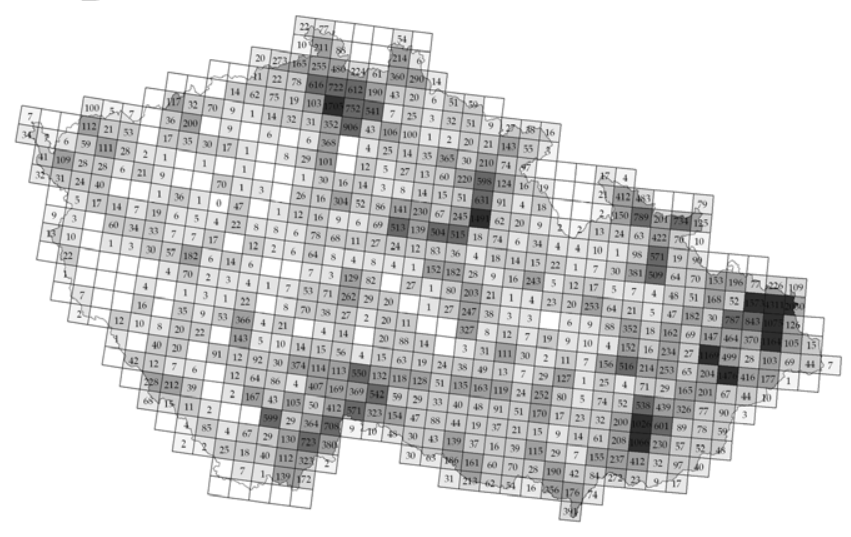

D

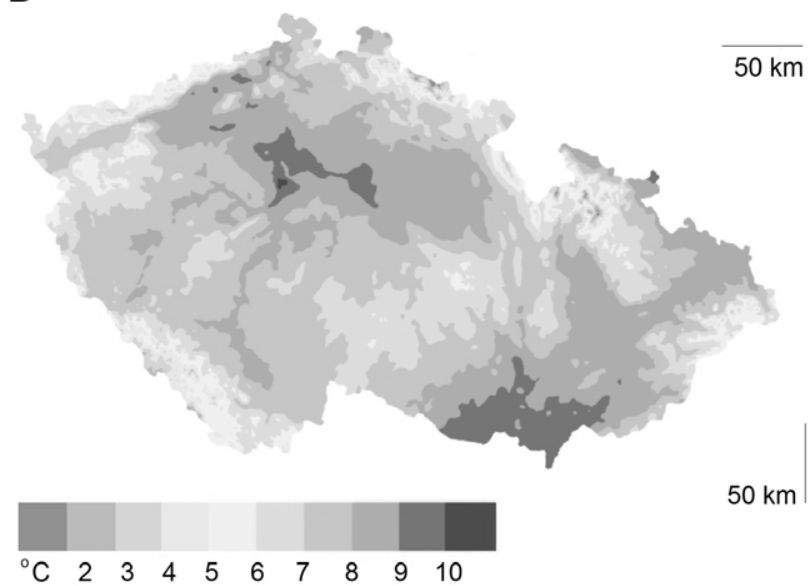

Fig. 1. Distribution of dragonflies and environmental conditions in the Czech Republic. The number of species (A) and records (B) per quadrat, and a relief map (C) and one showing average annual air temperatures (D) (Source: CHMÚ).

\section{Relative distribution}

First the number of species was regressed against the number of records per quadrat in order to identify the effect of unequal sampling of particular quadrats. The residuals from this regression were used in the subsequent analysis. The relative distribution was used as the dependent variable. The area of occupancy was measured as the number of quadrants, the dimensions of which were $10^{\prime}$ longitude $\times 6^{\prime}$ latitude, i.e., approximately $12 \times 11 \mathrm{~km}$. Altogether 72,868 data points from 7,255 localities and 593 from a total of 678 quadrats were used in the analysis of the distribution of dragonflies in the Czech Republic (Dolný et al., 2007). Of the quadrats, $87.5 \%$ had at least one record (Fig. 1). The results for the regionally extinct species were not included in the statistical analysis.

\section{Dispersal ability}

Estimating dragonfly dispersal ability is difficult. There are several ways of estimating the dispersal ability of dragonfly adults (Conrad et al., 1999, 2002; Watts et al., 2007; Wikelski et al., 2006) but it is known for only a small number of species. Hence, a modified method for estimating relative dispersal previously used for butterflies (Cowley et al., 2001) was used. A questionnaire was sent to 78 experienced odonatologists in Europe, which asked them to assign a "dispersal ability index" $(1-4)$ to each dragonfly species. In the questionnaire, a value of 1 indicated that a species was extremely sedentary and 4 indicated it had high dispersal ability. This ranking reflects the pro- portion of replies that classified a species as more, less, or of equal dispersal ability to every other species. Altogether, the results from 19 questionnaires were used in the analysis.

\section{Habitat specificity}

The habitat specificity of each species was classified according to its niche breadth, which is the number of (only autochthonous occurrences were recorded) the 18 habitat types occupied. The 18 potential natural and man-made freshwater dragonfly habitats included all the main freshwater biotopes in the Czech Republic. The 18 habitat types were: 1. temporary water bodies, puddles, temporary pools in grassland (pluviotelms); 2. garden pools; 3 . wetland pools; 4. glacial lakes, tarns; 5. oxbow lakes (paleopotamon); 6. reservoirs in valleys; 7. pools in quarries and gravel pits; 8 . farm ponds, intensive fishponds; 9. ponds with extensive fish culture, forest ponds; 10. raised bogs, acid peat-bog pools, transition mires; 11. fens; 12. specific industrial still waters (e.g., mining ponds); 13. springs and headwaters; 14. upper reaches; 15 . middle reaches (with pools and riffles); 16. lowland rivers; 17. artificial canals and drainage channels, ditches; and 18. polluted rivers.

\section{Range of altitudes}

The range between the lowest and highest altitude of recorded locations was used to obtain a basic knowledge about the distribution of appropriate habitats. The number of degrees of altitude occupied (100 m corresponds to one degree) was used in the 

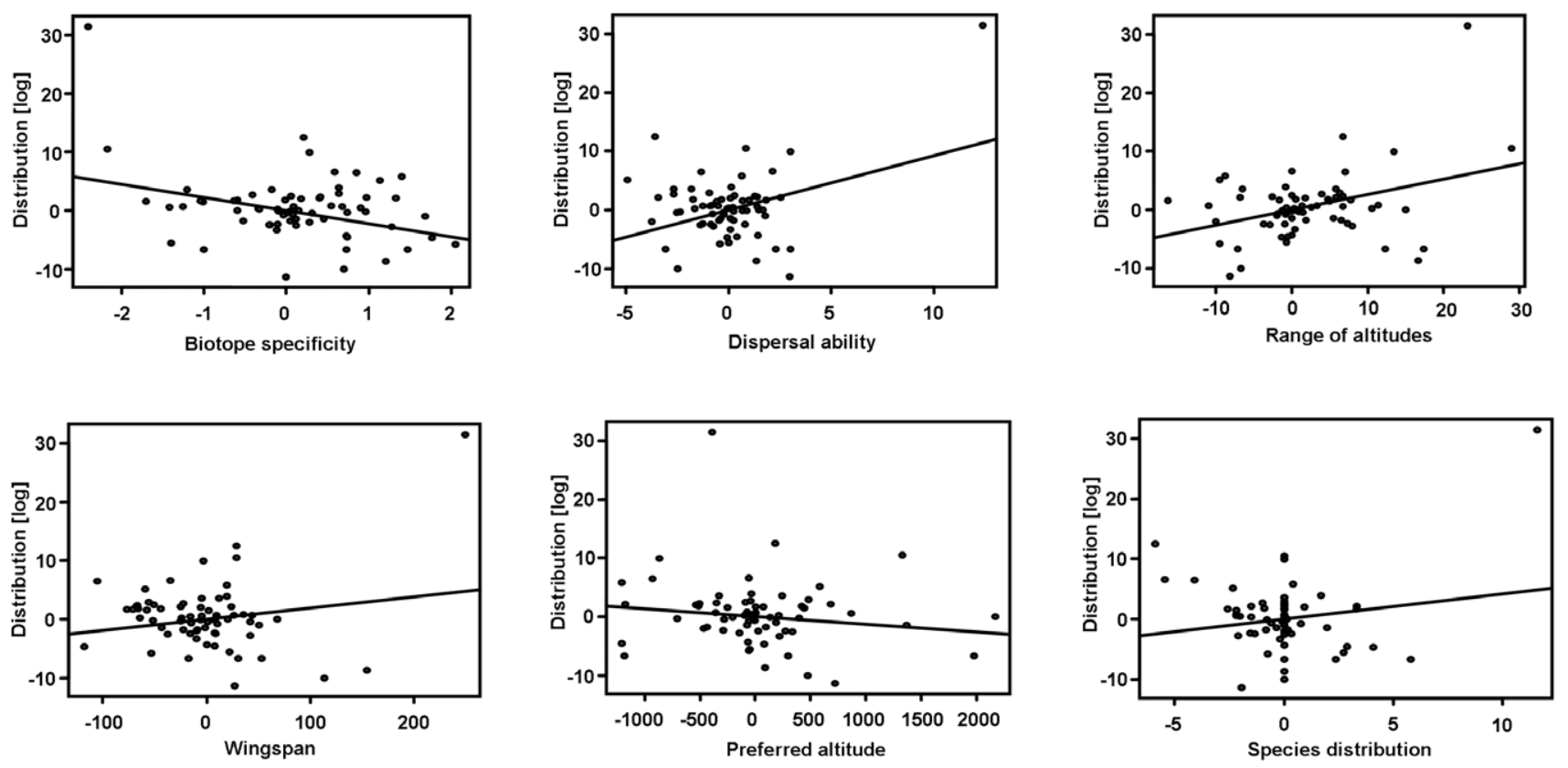

Fig. 2. Factors associated with the relative distribution of dragonflies after phylogenetic correction.

analysis. Random occurrences (less than 2\% occupancy for each species) were not used.

\section{Preferred altitude}

Altitude could be one of the most important environmental variables explaining the variation in dragonfly species composition. The average altitude at which each dragonfly species was recorded was calculated. The preferences of individual species are expressed as means of their hypsometric frequency. Some species that occur in a wide range of habitats prefer low altitudes and therefore never occupy all of the potentially suitable freshwater habitats (according to their habitat specificity). There is evidence that temperature greatly affects dragonfly ecology (mainly phenology) and distribution (Dingemanse \& Kalkman, 2008; Hickling et al., 2005) and temperature is negatively correlated with altitude.

\section{Species distribution}

Populations of species at the edge of their distribution tend to be less abundant and occupy a narrower range of habitats (Samways, 2003; Thomas et al., 1999) than in the centre of their distribution. The location of species within the distribution range of the Czech Republic was divided into three categories: 1. Main range, 2. Edge of the range and 3. Isolated population. This grid was overlaid on the range maps in Dijkstra \& Lewington (2006) and the presence of each species was recorded in each of these distribution ranges.

\section{Flight period}

The difference between the stability of weather conditions during spring and summer could significantly affect the ecology (Corbet, 1999; Thompson, 1990) and distribution of dragonflies. The dragonfly species occurring in the Czech Republic were categorized in terms of their phenology as either: spring, spring to summer, summer, summer to late summer, late summer, late summer to autumn, phenologically little-specialized species spanning more than one phenophase or species occurring nearly all year round with hibernating imagos.

The effect of time stress, forcing species to emerge even when conditions are suboptimal, is affected by the adaptive response of particular species (Stoks et al., 2008). The average flight period (the date by which half the population has emerged) was used to separate the spring and summer species occurring in the Czech Republic.

\section{Development and overwintering stage}

The duration of the life cycles of different dragonfly species vary greatly (Corbet, 1999) and this variation is associated with life history and stress factors (McCauley, 2007; Stoks et al., 2008). The length of the life cycle is linked to the overwintering stage (egg, larva, or adult). The negative effect of oxygen stress could increase the mortality of overwintering stages but the response of particular life stages to this factor could be different (Corbet, 1999). The average length of life cycle taken from various sources (Jödicke, 1997; Martens, 1996; Peters, 1987; Rüppell et al., 2005; Suhling \& Müller, 1996; Wildermuth, 2008) was used.

\section{Body size}

The male wing span $(\mathrm{mm})$ was used as a measure of dragonfly body size because this measurement is readily available and is one of the least variable parameters of size. The information in Watson \& Dallwitz (2009) was used, in which the $\pm 10 \%$ variability of samples is tolerable. The information for species that do not occur in the British Isles (i.e., not covered by Watson \& Dallwitz, 2009) was obtained from Dijkstra \& Lewington (2006).

TABLE 1. Factors significantly associated with the relative distribution of dragonflies at a regional scale based on an analysis that was not controlled for phylogeny.

\begin{tabular}{lccccr}
\hline Factor & $D f \begin{array}{c}\text { Deviance } \\
\text { Resid. }\end{array}$ & $\begin{array}{c}D f \\
\text { Resid. }\end{array}$ & Dev. & $P(>\mid$ Chi $\mid)$ \\
\hline NULL & & & 67 & 61.9 & \\
Species distribution & 2 & 37.96 & 65 & 23.9 & $<0.001$ \\
Biotope specificity & 1 & 3.42 & 64 & 20.5 & $<0.001$ \\
Dispersal ability & 1 & 1.55 & 63 & 19.0 & 0.004 \\
Range of altitudes & 1 & 1.20 & 62 & 17.8 & 0.012 \\
Preferred altitude & 1 & 3.05 & 61 & 14.7 & $<0.001$ \\
Wingspan & 1 & 0.39 & 60 & 14.3 & 0.153 \\
\hline
\end{tabular}




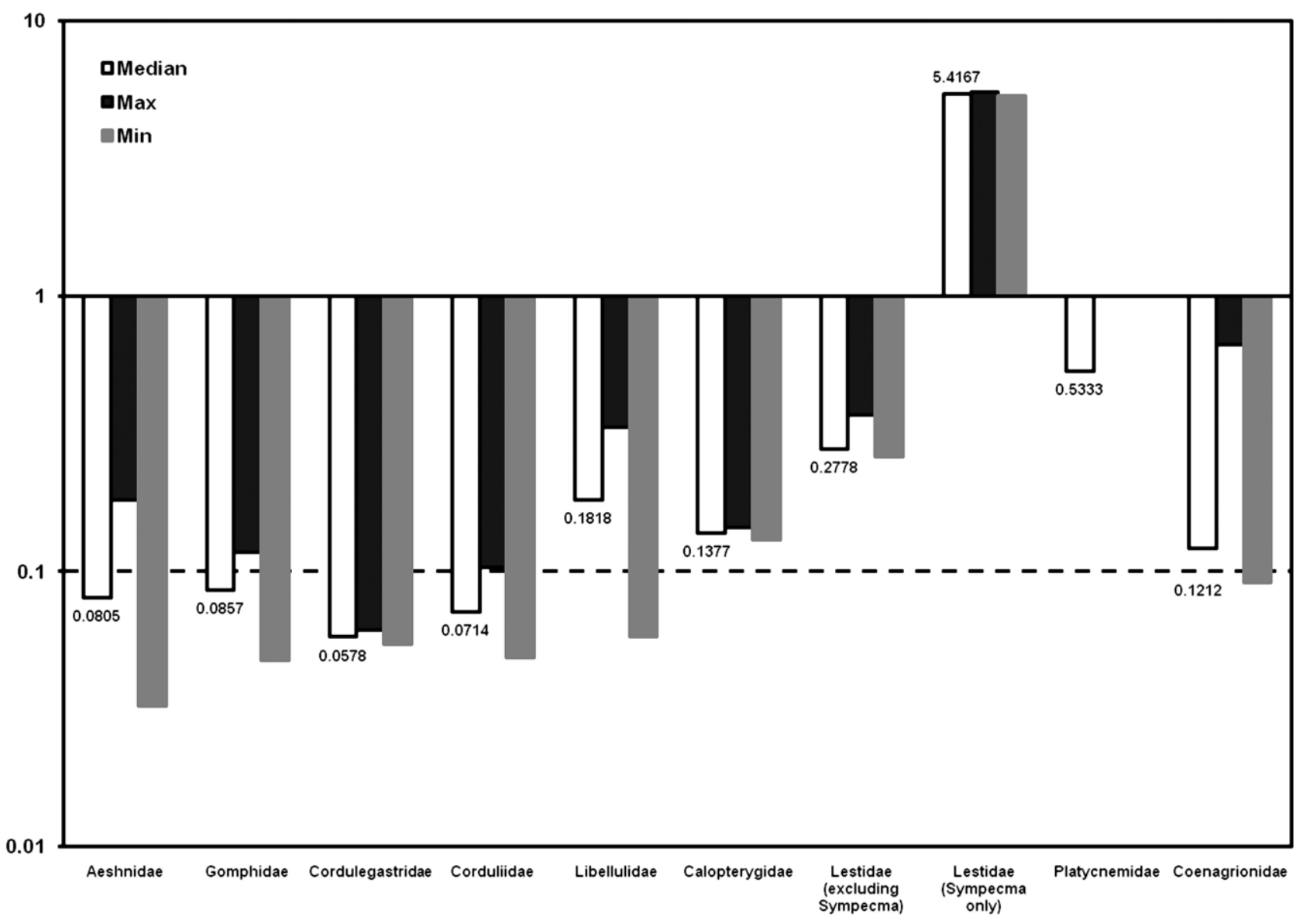

Fig. 3. The ratio of the length of the flight period to that of development for particular dragonfly families.

\section{Statistical analysis}

Before the general analysis the relative distribution was tested for normality using the Shapiro-Wilk test. Because the data was very variable a logit model, gamma distribution with control for overdispersion was used in the general analysis. A general linear model (GLM) was used to determine the association of various factors with relative distribution (R Development Core Team, 2007). The relative distribution was always the dependent value. Possible interactions among the factors were also tested but no significant interactions were found.

Because a complete phylogeny of Czech dragonflies is not available, a phylogenetic tree based on hierarchical taxonomy was developed. The phylogenic categories used in the analysis were: suborder; superfamily; family; genus; species. The phylogenic relationships for this analysis were taken from Schorr et al. (2009). The lengths of particular tree branches were modeled according Grafen (1989). Then, a phylogenic correction was

TABLE 2. Factors significantly associated with the relative distribution of dragonflies at a regional scale based on an analysis that was controlled for phylogeny.

\begin{tabular}{|c|c|c|c|c|c|c|}
\hline Factor & $D f$ & $\begin{array}{c}\text { Deviance } \\
\text { Resid. }\end{array}$ & $\begin{array}{c}D f \\
\text { Resid. }\end{array}$ & Dev. & $F$ & $\begin{array}{c}P r \\
(>F)\end{array}$ \\
\hline$\overline{\mathrm{UL}}$ & & & 67 & 2468 & & \\
\hline necies & 2 & 65.59 & 66 & 217 & & J \\
\hline & 1 & & 66 & & & 0.004 \\
\hline is & 1 & 298 & 66 & 194 & 10 & 0.002 \\
\hline & 1 & 30 & 66 & 19 & 10 & 0.002 \\
\hline & 1 & & 66 & 2194.4 & 1.37 & 0.247 \\
\hline Wingspan & 1 & 74.23 & 66 & 2165.6 & 2.26 & 0.137 \\
\hline
\end{tabular}

made using independent contrasts (Felsenstein, 1985). At first, a fully dichotomous tree was created. Initial observations of the variables were replaced by $n-1$ contrasts and each contrast was standardized with the root of the distance between adjacent species. Finally, the standardized contrasts of dragonfly distribution were regressed against the standardized contrasts of environmental factors, which were significant in the analysis that was not controlled for phylogeny.

\section{RESULTS}

Only five factors are significantly associated with the relative distribution of dragonflies (Table 1). The strongest is species distribution and more specifically, marginality $(P<0.001)$. The result of the phylogenetically controlled analysis indicates that marginality is associated with the phylogenetic relationship of dragonfly taxa $(P=0.163)$. Dragonfly species with marginal distributions are scarce (Fig. 2) and prefer a different spectrum of biotopes than species that occur within the main distribution range. Altitude preference is similarly significantly associated with distribution $(P<0.001)$. The species preferring high altitudes are scarcer than those preferring low altitudes. The preferences for specific altitudes are very similar for closely related taxa $(P=0.247)$.

Habitat specificity is another important factor associated with relative distribution $(P<0.001)$; habitat specificity was significant even in the phylogenetically controlled analysis $(P=0.004)$. This means that a species 
with very specific habitat requirements is likely to have a low probability of finding a suitable biotope for development (Fig. 2) and that closely related taxa can have distinct habitat preferences.

Dispersal ability is also significantly associated with the distribution of dragonflies $(P=0.004)$. Surprisingly, the dispersal abilities of even closely related taxa differ $(P=$ 0.002 ) according to the phylogenetically controlled analysis (Table 2). The species that occur over a broad range of altitudes are significantly more common $(P=$ 0.012 ) than those occurring over a narrow range of altitudes. The significance of this relationship is not related to any phylogenetic relationship $(P=0.002)$.

Relative distribution was not associated with the length of the adult flight period or the length of larval development. This result is surprising, given that the larval stage is the longest life stage in most dragonfly species (Fig. 3). For example, the larval stage is 17.3 times longer than the adult stage in the family Cordulegastridae. In contrast, the adult stage is 5.4 times longer than the larval stage in the genus Sympecma. Species with small wingspans are less common but their relative distribution is not associated with wingspan.

\section{DISCUSSION}

The distribution of dragonflies is not significantly associated with adult flight period or the length of larval development. The relative distribution of dragonflies, and especially changes in distribution, is not primarily associated with larval life history, although the adult stage is considerably shorter than that of the larvae in most species (Fig. 3). Larval adaptations probably mainly affect distribution at a local level (McCauley, 2007) and dispersal by the more mobile adults, mainly regional distribution (Hof et al., 2006).

A life history that is substantially different from that of most other species is represented by species of the genus Sympecma (Lestidae), which overwinter in the adult stage (Corbet, 1999). The longest life stage of Sympecma spp. is the adult, and the risk of overwintering mortality is reduced by a number of unique morphological and behavioural adaptations (Manger \& Dingemanse, 2009). These adaptations could be considered a trade off. Whereas the competition among dragonfly larvae is usually highest in spring due to limited resources that among adults is usually minimal in spring but increases during the season (Crumrine et al., 2008). It is possible that there is a trade off in Sympecma spp. between the increased risk of mortality in winter and the reduced competition for adult niches in spring. In other words, by overwintering, adults of Sympecma spp. avoid intense inter-specific competition.

In agreement with our initial hypothesis, habitat specialists are rarer then species utilizing a broad spectrum of habitats. Like Korkeamäki \& Suhonen (2002), it is concluded that habitat specificity is the most significant factor associated with the distribution of dragonflies. However, there are considerable differences even among the distributions of habitat specialists. The preference for specific altitudes should be also evaluated as part of habitat specificity. In particular, those species that prefer biotopes located at high altitudes are scarce because there is less availability of water biotopes at high than at low altitudes. The preference for specific altitudes is markedly associated with the phylogenetic relatedness of Central European dragonfly species (Table 2). Like species distribution, the preference for specific altitudes may be correlated with species' dispersion in the postglacial period (see Sternberg, 1998).

In many cases it is very difficult to objectively determine if a given dragonfly species is really endangered. A narrow niche implies that there are very few suitable biotopes for a given species. The distribution of suitable biotopes varies considerably.

The preference for a specific altitude range is not significantly associated with distribution in this analysis. Species that are distributed over a broad altitudinal range have a high probability of finding a suitable biotope. Temperature is a limiting factor especially for Mediterranean species, which have been moving northwards in the last few decades (Hickling et al., 2005). The distribution of Mediterranean species in the Central European region is limited to low altitudes (Dolný et al., 2007).

Species with limited distribution, whose boundaries encroach upon Central Europe only marginally, vary in abundance and prefer a broader spectrum of biotopes in the centre of the range. Marginality is a very important feature associated with the distribution of dragonflies (Samways, 2003). The significance of this factor is markedly affected by the phylogenetic relationship, which may be correlated with species dispersion in the postglacial period (see Sternberg, 1998). This difficult-to-quantify factor should be kept in mind when measuring species distribution, especially national red list classified species (Samways, 2003).

It is not surprising that relative dispersal ability is not significantly associated with distribution. The importance of this factor could perhaps be underestimated, because our knowledge of the dispersal ability of particular species is very limited (Bohonak \& Jenkins, 2003). The tendency to disperse is markedly high in juvenile (teneral) stages and there are considerable differences between and within suborders (May \& Corbet, 2007) and between sexes, with especially the females of territorial species showing a high tendency to disperse (see Corbet, 1999). The very limited dispersal ability of habitat specialists could increase their risk of extinction (Watts et al., 2004). Metapopulation dynamics could also play a very important role (Bohonak \& Jenkins, 2003) and represent a key strategy enabling survival in an unstable environment.

Body and wing size evolved as a complex trade off between flying ability and energy expenditure (Marden, 2008). A greater body size may not necessarily be linked with better dispersal ability.

\section{CONCLUSION}

Habitat specificity significantly affects population ecology and is negatively associated with the distribution 
of dragonflies. Habitat generalists inhabit a wide range of habitats at different altitudes and have high dispersal ability. All these qualities should be considered as evolutionarily advantageous in the context of anthropogenic environmental changes. Marginality of species' distribution as a result of the re-colonization of Central Europe after the last glaciation is negatively associated with the distribution of dragonflies.

ACKNOWLEDGEMENTS. This study was funded by grant No. SM/6/104/05 from the Ministry of the Environment of the Czech Republic, grant No. 206/07/0811 from the Grant Agency of the Czech Republic and grant No. 200942110006 from IGA Czech University of Life Sciences Prague. We would like to thank H. Wildermuth and J. Šipoš for their support and valuable comments on the manuscript. We thank the Czech Union for Nature Conservation (CSOP) for providing us with the database.

\section{REFERENCES}

BohonaK A.J. \& Jenkins D.G. 2003: Ecological and evolutionary significance of dispersal by freshwater invertebrates. Ecol. Lett. 6: 783-796.

Bried J.T., Herman B.D. \& Ervin G.N. 2007: Umbrella potential of plants and dragonflies for wetland conservation: a quantitative case study using the umbrella index. J. Appl. Ecol. 44: 833-842.

Conrad K.F., Willson K.H., Harvey I.F., Thomas C.J. \& SherRATT T.N. 1999: Dispersal characteristics of seven odonate species in an agricultural landscape. Ecography 22: 524-531.

ConRad K.F., Willson K.H., WhitField K., Harvey I.F., Thomas C.J. \& SherRatT T.N. 2002: Characteristics of dispersing Ischnura elegans and Coenagrion puella (Odonata): age, sex, size, morph and ectoparasitism. Ecography 25: 439-445.

Corbet P.S. 1999: Dragonflies: Behaviour and Ecology of Odonata. Harley Books, Colchester, 829 pp.

Corbet P.S. \& MAY M. 2008: Fliers and perchers among Odonata: dichotomy or multidimensional continuum? A provisional reappraisal. Int. J. Odonatol. 11: 155-172.

Cowley M.J.R., Thomas C.D., Roy D.B., León-Cortés J.L., GutiérRez D. \& Bulman C.R. 2001: Density-distribution relationships in British butterflies. I. The effect of mobility and spatial scale. J. Anim. Ecol. 70: 410-425.

Crumrine P.W., Switzer P.V. \& Crowley P.H. 2008: Structure and dynamics of odonate communities: accessing habitat, responding to risk, and enabling reproduction. In CórdobaAguilar A. (ed.): Dragonflies and Damselflies. Model Organisms for Ecological and Evolutionary Research. Oxford University Press, Oxford, pp. 21-39.

D'Amico F., Darblade S., Avignon S., Blanc-Manel S. \& ORMEROD S.J. 2004: Odonates as indicators of shallow lake restoration by liming: comparing adult and larval responses. Restor. Ecol. 12: 439-446.

Dijkstra K.B. \& Lewington R. 2006: Field Guide to the Dragonflies of Britain and Europe. British Wildlife Publishing, Gillingham, $320 \mathrm{pp}$.

Dingemanse N.J. \& Kalkman V.J. 2008: Changing temperature regimes have advanced the phenology of Odonata in the Netherlands. Ecol. Entomol. 33: 1-9.

Dolný A., Bárta D., Waldhauser M., Holuša O. \& Hanel L. 2007: The Dragonflies of the Czech Republic: Ecology, Conservation and Distribution. Český svaz ochránců přírody Vlašim, Vlašim, 672 pp.

Felsenstein J. 1985: Phylogenies and the comparative method. Am. Nat. 125: 1-15.
Foote A.L. \& Hornung C.L.R. 2005: Odonates as biological indicators of grazing effects on Canadian prairie wetlands. Ecol. Entomol. 30: 273-283.

Grafen A. 1989: The phylogenetic regression. Phil. Trans. R. Soc. (B) 326: 119-157.

Hassall C., Thompson D.J. \& Harvey I.F. 2010: The impact of climate-induced distributional changes on the validity of biological water quality metrics. Envir. Monit. Assessm. 160: 451-456.

Hickling R., Roy D.B., Hill J.K. \& Thomas C.D. 2005: A northward shift of range margins in British Odonata. Glob. Change Biol. 11: 502-506.

Hof C., Brändle M. \& Brandl R. 2006: Lentic odonates have larger and more northern ranges than lotic species. J. Biogeogr. 33: 63-70.

JöDICKE R. 1997: Die Binsenjungfern und Winterlibellen Europas: Lestidae (Die Neue Brehm-Bücherei; Bd. 631, Die Libellen Europas-Band 3). Westarp Wissenschaften, Magdeburg, $277 \mathrm{pp}$.

Johansson F., Englund G., Brodin T. \& Gardfjell H. 2006: Species abundance models and patterns in dragonfly communities: effects of fish predators. Oikos 114: 27-36.

KeIL P., Śímová I. \& Hawkins B.A. 2008: Water-energy and the geographical species richness pattern of European and North African dragonflies (Odonata). Insect Conserv. Divers. 1: $142-150$.

KorkeAmÄKI E. \& SUHONEN J. 2002: Distribution and habitat specialization of species affect local extinction in dragonfly Odonata populations. Ecography 25: 459-465.

Manger R. \& Dingemanse N.J. 2009: Adult survival of Sympecma paedisca (Brauer) during hibernation (Zygoptera: Lestidae). Odonatologica 38: 55-59.

MARDEN J.H. 2008: Dragonfly flight performance: a model system for biomechanics, physiological genetics, and animal competitive behaviour. In Córdoba-Aguilar A. (ed.): Dragonflies and Damselflies. Model Organisms for Ecological and Evolutionary Research. Oxford University Press, Oxford, pp. 249-261.

Martens A. 1996: Die Federlibellen Europas (Platycnemididae) (Die Neue Brehm-Bücherei; Bd. 626, Die Libellen Europas-Band 1). Westarp Wissenschaften, Magdeburg, 149 pp.

MCCAULEY S.J. 2007: The role of local and regional processes in structuring larval dragonfly distributions across habitat gradients. Oikos 116: 121-133.

McCauley S.J. 2008: Slow, fast and in between: habitat distribution and behaviour of larvae in nine species of libellulid dragonfly. Freshw. Biol. 53: 253-263.

McPeek M.A. 1989: Differential dispersal tendencies among Enallagma damselflies (Odonata: Coenagrionidae) inhabiting different habitats. Oikos 56: 187-195.

McPeeK M.A. 2004: The growth/predation risk trade-off: So what is the mechanism? Am. Nat. 163: 88-111.

Peters G. 1987: Die Edellibellen Europas: Aeshnidae (Die Neue Brehm-Bücherei; Bd. 585). Ziemsen Verlag, Wittenberg Lutherstadt, $140 \mathrm{pp}$.

R Development Core Team 2007: R: A Language and Environment for Statistical Computing. R Foundation for Statistical Computing, Vienna, Austria. Available from URL: http://www.R-project.org.

Remsburg A.J., Olson A.C. \& Samway M.J. 2008: Shade alone reduces adult dragonfly (Odonata: Libellulidae) abundance. $J$. Insect Behav. 21: 460-468.

Rüppell G., Rehfeldt G., Schütte C., Hilfert-Rüppell D. \& Lindeboom M. 2005: Die Prachtlibellen Europas (Calopteryx). (Die Neue Brehm-Bücherei; Bd. 654, Die 
Libellen Europas-Band 4). Westarp Wissenschaften, Hohenwarsleben, $255 \mathrm{pp}$.

SAhlen G. \& Ekestubbe K. 2001: Identification of dragonflies (Odonata) as indicators of general species richness in boreal forest lakes. Biodivers. Conserv. 10: 673-690.

SAmways M.J. 2003: Marginality and national red listing of species. Biodivers. Conserv. 12: 2523-2525.

Schindler M., Fesl C. \& Chovanec A. 2003: Dragonfly associations (Insecta: Odonata) in relation to habitat variables: a multivariate approach. Hydrobiologia 497: 169-180.

Schorr M., Lindeboom M. \& Paulson D. 2009: World Odonata List. Slater Museum of Natural History, University of Puget Sound, Tacoma, WA, http://www.ups.edu/x6140.xml.

Smith J., Samways M.J. \& Taylor S. 2007: Assessing riparian quality using two complementary sets of bioindicators. Biodiv. Conserv. 16: 2695-2713.

SternBerg K. 1998: Die postglaziale Besiedlung Mitteleuropas durch Libellen, mit besonderer Berücksichtigung Südwestdeutschlands. J. Biogeogr. 25: 319-337.

Stoks R., Johansson F. \& De Block M. 2008: Life-history plasticity under time stress in damselfly larvae. In CórdobaAguilar A. (ed.): Dragonflies and Damselflies. Model Organisms for Ecological and Evolutionary Research. Oxford University Press, Oxford, pp. 39-51.

SuHLIng F. \& Müller O. 1996: Die Flussjungfern Europas: Gomphidae (Die Neue Brehm-Bücherei; Bd. 628, Die Libellen Europas-Band 2). Westarp Wissenschaften, Magdeburg, Heidelberg, 237 pp.

Thomas J.A., Rose R.J., Clarke R.T., Thomas C.D. \& Webb N.R. 1999: Intraspecific variation in habitat availability among ectothermic animals near their climatic limits and their centres of range. Funct. Ecol. 13: 55-64.

THOMPson D.J. 1990: The effects of survival and weather on lifetime egg production in a model damselfly. Ecol. Entomol. 15: 455-462.

Watson L. \& Dallwitz M.J. 2009: British Insects: The Odonata (Dragonflies and Damselflies). Version: 31st May 2009. http://delta-intkey.com/britin/odo/www/ident.htm

Watts P.C., Rouquette J.R., Kemp S.J. \& Thompson D.J. 2004: Molecular and ecological evidence for small-scale isolation by distance in an endangered damselfly, Coenagrion mercuriale. Mol. Ecol. 13: 2931-2945.

Watts P.C., Rousset F., Saccheri I.J., Leblois R., Kemp S.J. \& Thompson D.J. 2007: Compatible genetic and ecological estimates of dispersal rates in insect. Mol. Ecol. 16: 737-751.

Whittaker R.J., Nogues-Bravo D. \& Araujo M.B. 2007: Geographical gradients of species richness: a test of the waterenergy conjecture of Hawkins et al. (2003) using European data for five taxa. Global Ecol. Biogeogr. 16: 76-89.

Wikelski M., Moskowitz D., Adelman J.S., Cochran J., WilCove D.S. \& MAY M.L. 2006: Simple rules guide dragonfly migration. Biol. Lett. 2: 325-329.

Wildermuth H. 2001: Das Rotationsmodell zur Pflege kleiner Moorgewässer. Simulation naturgemäßer Dynamik. SchrReihe Landschaftspfl. Natursch. 33: 269-273.

Wildermuth H. 2008: Die Falkenlibellen Europas: Corduliidae (Die Neue Brehm-Bücherei 653, Die Libellen Europas-Band 5). Westarp Wissenschaften, Hohenwarsleben, 496 pp.

Received December 18, 2009; revised and accepted May 17, 2010 